\title{
Teaching with wikis: improving staff development through action research
}

\author{
Robyn Benson ${ }^{a *}$, Charlotte Brack ${ }^{\mathrm{a}}$, and Gayani Samarwickrema ${ }^{\mathrm{b}}$ \\ ${ }^{a}$ Faculty of Medicine, Nursing and Health Sciences, Monash University, Melbourne, Australia; \\ ${ }^{b}$ Faculty of Health, Deakin University, Melbourne, Australia
}

(Received 17 May 2011; final version received 30 September 2011)

\begin{abstract}
This paper reports on the use of action research in a case study involving two iterations of an online workshop implemented at two universities in late 2007 and early 2009 to prepare teaching staff for using wikis for student group work and assessment. Workshop participants were immersed in the experience of collaborating in a wiki as learners and then reflected on this experience as teachers. Experience of the pilot workshop suggested a need for more orientation, potentially by introducing a blended learning design. The second iteration highlighted a need to develop the orientation session further and increase support strategies throughout the workshop, suggesting the value of offering it at faculty or department level if no "reward" is available for participation. Outcomes from the two cycles illustrate the value of action research for iterative improvement of this staff development model and for implementing the scholarship of teaching and learning to develop and share professional knowledge in this emerging area. This paper outlines a staff development approach involving Web 2.0 applications on which others can build.
\end{abstract}

Keywords: action research; scholarship of teaching and learning; staff development; social software; Web 2.0

\section{Introduction}

This paper draws on the idea of the scholarship of teaching and learning as an action research process with rigour achieved through responsiveness to practice (Schön 1995). We used this process to drive the design, implementation and improvement of an online staff development model to prepare teaching staff at two Australian universities for using wikis for student group work and assessment. Our aim was to use action research to refine, iteratively develop and evaluate the workshop model and make our findings available for use by others. This was based on the assumption that identifying approaches for assisting staff to teach with emerging technologies is an important aspect of enquiry to counter the typically slow adoption of educational technologies by academics (Birch and Burnett 2009). It also supports the concept of teachers becoming reflective practitioners to capture and reuse the pedagogic forms they create when using learning technologies, so that exploration of innovative pedagogy "take[s] on the character of research - a more rigorous way of developing our knowledge in this critically important field" (Laurillard 2008, p. 153).

*Corresponding author. Email: robyn.benson@monash.edu 
Our specific research questions were the following:

(1) How effective is this online staff development model in helping staff to use wikis for student group work and assessment?

(2) What implications for improving the model emerged over two action research cycles?

(3) Is action research a useful approach for the iterative development of this workshop?

A further aim of this paper is to demonstrate how promoting change in specific situations through action research (Kember and Kelly 1993) can contribute more broadly to building knowledge through the scholarship of teaching and learning.

While understandings of what the scholarship of teaching and learning involves vary (e.g., Boshier 2009; Brew 2006; Norton 2009), we characterise it as a form of enquiry (Hutchings and Shulman 1999) where knowledge about teaching is renewed when teachers' work 'becomes public, peer-reviewed and critiqued, and exchanged with other members of our professional communities so they, in turn, can build on our work" (Shulman 2000, p. 49). Norton (2009) suggests that pedagogical action research is a compelling way of engaging with the scholarship of teaching and learning. The emergent nature of knowledge about e-learning appears to lend itself to the rapid sharing of experiences captured through such processes, so that advances in pedagogy do not lag behind advances in technology.

We begin by outlining the potential implications for teaching and learning of Web 2.0 applications such as wikis. We then consider these in the context of staff development approaches for online teaching, before focusing on the use of action research for informing staff development. We explain how action research was used iteratively in our case study to prepare staff for teaching with wikis. We then report on the knowledge gained from this experience and discuss its implications.

\section{Conceptual background}

\section{Web 2.0 applications}

The ability of Web 2.0 applications to support online group interaction offers important benefits for teaching and learning. As one of these applications, wikis provide an online space where students can write, edit and construct knowledge together, taking greater responsibility for and control of their learning. These features present new challenges in designing learning and assessment tasks that accommodate the "wisdom of crowds" (Surowiecki 2004). This University 2.0 environment (Barnes and Tynan 2007) requires teachers to relinquish control and permit organic and emergent structures to arise from group interactions (Dron 2007). It also offers potential for enquiry into teaching and learning, which focuses on how teaching staff can support learning in this setting and on how students build knowledge through virtual collaboration (e.g., Guo and Stevens 2011; Ruth and Houghton 2009; Su and Beaumont 2010).

\section{Staff development for online teaching}

An underlying challenge for teaching staff is to learn to use these new tools and apply them in pedagogically effective ways. Wilson and Stacey (2004) reviewed programs for 
preparing staff for online teaching, emphasising the importance of situating learning activities in authentic contexts and offering opportunities for staff to share experiences, ideas and reflections as they engage as learners. Doherty (2011) supports the value of a project-based approach for Web 2.0 staff development. Situated learning allows participants to experience the complexity and ambiguity of real world challenges, embedding learning in the social context in which it will be used (Brown, Collins, and Duguid 1989). Using the social context to reflect on learning highlights the value of communities of practice where groups of people with common interests "deepen their knowledge and expertise ... by interacting on an ongoing basis" (Wenger, McDermott, and Snyder 2002, p. 4). This approach draws on social constructivism (Vygotsky 1978) for explaining social engagement online. Garrison and Anderson (2003) describe how teachers and learners may engage in an educational community of enquiry, encouraging both cognitive independence and social interdependence. These ideas underpinned our workshop design while action research guided its continuing improvement.

\section{Action research}

Action research offers many benefits for enquiry into teaching and is an established model for staff development in higher education (Grundy 1995; Kember and Gow 1992; Webb 1996). Its cyclical character, involving planning, action, observation and reflection, supports critically reflective thinking about one's own practice, is grounded in the use of collaboration to forge new meanings from experience and offers a clear framework for action (Brookfield 1995; Carr and Kemmis 1986; Kemmis and McTaggart 2005). Its iterative nature, facilitated by reflection, appears appropriate to the evolving state of knowledge in the area, allowing for incremental accumulation and sharing of new ways to enhance student learning.

Action research typically begins with a pedagogical problem, paradox, issue or difficulty (Norton 2009), which invites enquiry and action by practitioners to address a concern that relates immediately to their teaching practice. It is usually associated with interpretive research methods and informed by a strong emphasis on the social, reflective and emancipatory aspects of critical social theory (Carr and Kemmis 1986). Implementation of the process is seen in different ways. For example, Norton (2009) regards the identification of the issue to be investigated as observation, which is then followed by planning, action and reflection. In contrast, Kember and Kelly (1993) describe the plan-act-observe-reflect sequence based on the seminal work of Lewin (1946), providing examples that begin with initial reflection to commence the planning process.

We adopted the latter approach but began with the planning phase. The pedagogical issue we were addressing was the need to explore ways to assist academic staff to use wikis for teaching and assessment. We planned to use an interpretive method, not only observing teaching staff engage in an immersive experience working in a wiki as students (the action) and recording our observations as an aspect of research but also including evaluation by participants as a research component. Critical reflection occurred initially with participants and then among ourselves as workshop designers and developers. Hence, the participatory nature of action research offered a way of conceptualising the investigative aspects of this project, informing ongoing staff development and, potentially, establishing a basis for future collaboration with workshop participants to generate new understandings about teaching with wikis. 


\section{R. Benson et al.}

The following sections outline how we used action research for planning, implementation and improvement. The method and results for each cycle are presented separately to demonstrate how the first cycle influenced the second in a process of iterative development. We then discuss implications from our experience of these two cycles.

\section{Method (Cycle 1)}

A description of the first cycle (Samarawickrema, Benson, and Brack 2008, 2010) is summarised here to provide a basis for explaining the modifications made during Cycle 2.

\section{Planning}

A key intention was that participants would work in two groups, each consisting of participants from both universities. As staff members of these universities we worked together in this project to address a pedagogical issue that was relevant to both institutions in exploring approaches for facilitating staff development in the use of new technologies. Since participants would be immersed in the experience of collaborating in a wiki as learners and then reflect on this experience as teachers, the workshop design consisted of two main stages: task completion (two weeks) and a debriefing phase over one week representing the reflection part of the action cycle. A primary workshop wiki called Wikis in Higher Education would provide the following:

(1) resources about using wikis in higher education;

(2) a workshop task;

(3) guidelines on working in a wiki; and

(4) links to two workshop wikis that participants would develop as "students."

The workshop task, designed to resemble a student group project, required an outcome that would allow assessment of both a group product and individual contributions. The task required participants to identify a student group project that could be undertaken in a wiki and then collaboratively develop a set of guidelines for their students, using the features of the wiki to present these guidelines. During the reflection phase, participants would be given access to the wiki of the other group and be asked to assess the group product and individual contributions to it. The Wikis in Higher Education site was available for interaction between participants and facilitators, but the workshop wikis were to "belong" to group members (Dron 2007) and have no facilitator involvement. Participants would not have access to the wiki belonging to the other group until debriefing.

Our role as facilitators during task completion would be to observe, answer questions and offer guidance via discussion on the Wikis in Higher Education site. We would then take a more proactive role during debriefing to facilitate feedback and reflection, summarise participant responses and share facilitator reflections.

\section{Action}

At University A (UA), invitations to participate were sent to staff from a single faculty selected for their prior involvement or interest in online learning, whereas an 
open invitation was sent to all staff at University B (UB). Thirteen volunteered (six from UA and seven from UB). We divided participants into two groups, giving Group 1 access to Workshop Wiki 1 and Group 2 access to Workshop Wiki 2. We began the workshop by emailing participants with instructions for logging into the Wikis in Higher Education site, inviting them to introduce themselves to other participants, identify their groups and locate their workshop wiki to complete the task over the following two weeks.

There were delays in group formation and task completion, and because participants did not return to the Wikis in Higher Education site for support as anticipated, we took a more proactive role, clarifying requirements on the Wikis in Higher Education site, sending group and individual emails to encourage and support participants and offering some guidance in the workshop wikis.

\section{Observation}

We monitored the sites daily, observing task progress, which resulted in the unplanned actions outlined above. We recorded our daily findings in an online diary.

\section{Reflection}

In the final week, we opened the workshop wikis to all participants and asked them to return to Wikis in Higher Education for debriefing, requesting them to:

(1) critique the other group's wiki and comment on the content, group effort and individual efforts;

(2) reflect and comment on the experience of working collaboratively in their wiki, identifying what they had learnt and ideas for using wikis in teaching and learning; and

(3) evaluate the workshop itself.

\section{Results (Cycle 1)}

\section{Task progress}

Task progress was slow. By the end of Week 1, four participants had accessed each workshop wiki but minimal progress had been made in Workshop Wiki 2. At the end of Week 2, five participants had accessed Workshop Wiki 1 and six had accessed Workshop Wiki 2. Workshop Wiki 1 was more advanced with three wiki pages (two of them incomplete). Group 2 created only one page.

\section{The debrief}

\section{Critique}

Workshop Wiki 1 participants commented that Workshop Wiki 2 was poorly proof read, was confined to the main page, lacked focus on the task and required better content organisation, noting that participants spent too much time on the task context rather than the task itself. In contrast, Workshop Wiki 2 participants were impressed with the group effort, content and navigation in Workshop Wiki 1. 


\section{Reflection}

Eight participants contributed reflections, suggesting that the workshop helped them to contextualise how to use wikis and introduce them to students. They felt they needed more time for discussion, planning, familiarisation with wiki functions, group formation and editing others' work.

\section{Evaluation}

Five participants contributed evaluation comments. The experience of participation was regarded as the most useful aspect but they expressed concerns about technical issues related to logging in, lack of familiarity with the wiki environment, insufficient time for the task and for group formation and a sense of needing more guidance.

\section{Our reflections}

We considered the basic workshop design to be appropriate, including the aims, objectives and structure. However, collaborative engagement between participants was inhibited by their previous level of technology adoption, unfamiliarity with the wiki environment, lack of time and technical issues, indicating a need for more orientation and support in both mastering the wiki tools and conceptualising engagement with others to create a group output. We also noted that the lack of "reward" for participation reduced the imperative to complete the task, unlike assessable student group work.

\section{Method (Cycle 2)}

\section{Planning}

Based on our experience, we planned a second workshop with a similar design but modified as follows:

(1) A face-to-face orientation session was added to clarify workshop aims and expectations and fast track group formation and interaction in the wiki.

(2) The Wikis in Higher Education site was replaced by a Blackboard site containing resources, instructions, discussion spaces and entry to the workshop wikis. As Blackboard was a familiar environment for participants, we expected improved access to and engagement in the wikis.

(3) Two parallel workshops were organised (one at each university), each with two wiki groups (i.e., a total of four groups). We expected participants to feel more comfortable working with colleagues from their own university. We planned to give participants access to all four wikis during debriefing and ask them to select one to critique, using an assessment rubric, which we would provide.

(4) Workshop duration was shortened to 10 days: eight for task completion and two for debriefing. Although pilot workshop participants had expressed the need for more time, the challenge of competing work pressures suggested that task completion might be assisted by maintaining momentum over a shorter time. We expected that the orientation session would address some of the issues that prompted a sense of insufficient time in the first workshop. 
(5) We advertised the workshops at both universities, offering a maximum of 12 places at each, with six participants per workshop group representing a manageable size. Although there would still be no reward for participation, we expected greater motivation to complete the workshop from self-initiated involvement. Again (because of the facilitators' institutional roles), participants were from a single faculty at UA but across the faculties at UB.

\section{Action}

Nine participants registered at UA and 12 at UB. At the face-to-face orientation sessions at each university, participants practised using wiki discussion, history and editing functions and began group formation by planning roles and responsibilities, communication strategies and timelines and brainstorming project ideas. As facilitators, we participated in both sessions. Following each session, we asked participants to complete an evaluation survey on their Blackboard site.

Participants then engaged in the online workshop task using similar instructions to those provided in the pilot workshop. We used the Blackboard mail and discussion tools to contact participants, answer queries, provide advice and offer reminders. At UA, two wiki server malfunctions interrupted progress, requiring explanatory communication via Blackboard. UA Group 1 members also used the discussion tool to contact each other and schedule their wiki contributions. At UB, group emails were sent to encourage and support participants, prompt completion of orientation session feedback, remind them of the impending workshop closure date, announce the start of the debriefing phase and reiterate debrief expectations.

\section{Observation}

As in the pilot workshop, we observed task progress daily throughout the action phase.

\section{Reflection}

For the final two days, we gave participants access to all four wikis and asked them to critique a wiki from either university (using the provided rubric for assessment of individual and group contributions and content). This was followed by reflection and evaluation as before, using tools provided on their Blackboard sites.

\section{Results (Cycle 2) \\ Orientation session}

All UA participants attended an orientation session, except one who was located at an overseas campus and supported by telephone. Two UA participants attended the UB session because of scheduling issues, joining nine of the 12 UB participants.

Table 1 summarises participants' survey responses, with multiple choice items scored from strongly agree (5) to strongly disagree (1) on a 5-point scale. These items were completed by the six participants at the UA session and the overseas-based participant. Seven of the $11 \mathrm{UB}$ attendees completed the survey, two of whom could have been the UA participants attending that session. 
Table 1. Responses to multiple choice items from the orientation session evaluation surveys.

\begin{tabular}{lcc}
\hline Multiple choice items & $\begin{array}{c}\text { UA mean } \\
\mathrm{n}=7\end{array}$ & $\begin{array}{c}\text { UB mean } \\
\mathrm{n}=7\end{array}$ \\
\hline $\begin{array}{l}\text { (1) I am clear about what is expected of me in the online workshop } \\
\text { project. }\end{array}$ & 4.14 & 3.14 \\
$\begin{array}{l}\text { (2) I am confident about using a wiki for project discussion, editing } \\
\text { and viewing the history of the project. }\end{array}$ & 3.14 & 3.71 \\
$\begin{array}{l}\text { (3) I am confident about working with members of my group in the } \\
\text { workshop project. }\end{array}$ & 4.14 & 3.71 \\
$\begin{array}{l}\text { (4) I can recognise how a group project in a wiki could be assessed } \\
\text { (including assessment of process and product, and of individual }\end{array}$ & 3.71 & 4.00 \\
$\begin{array}{l}\text { and group contributions). } \\
\text { (5) I know how to access support during the project if I need it. }\end{array}$ & 4.57 & 3.71 \\
\hline
\end{tabular}

Results indicated moderate to high levels of satisfaction with the orientation session. UA participants were most confident about accessing support (4.57) while UB participants were most confident in recognising how a group project in a wiki could be assessed (4.00).

Participants were also asked about changes that would have improved their preparation for the online workshop and for comments about any other aspects of the session. UA comments indicated interest in the potential of wikis and the logistics of setting them up and suggested an increased timeframe for the session. UB suggestions included running a prior technical workshop on wikis, providing printed (rather than online) help on creating wiki pages and having only one orientation session presenter with other facilitators assisting. However, comments indicated that "[I]t was well set out" and that "[T]he session was very enjoyable and ... [has] great possibilities."

\section{Task progress}

Eight of the UA participants contributed to wiki development, four in each group. Each group created eight wiki pages, but while Group 2 populated all, Group 1 populated five of their pages. UB participants were divided into two groups of six. Five were active in one wiki, creating six pages, and three in the other, creating three pages. Table 2 summarises the number of page edits and discussion contributions by each participant.

Table 2. Edits and discussion contributions per participant.

\begin{tabular}{|c|c|c|c|c|c|c|c|c|}
\hline \multirow[b]{3}{*}{ Participant } & \multicolumn{4}{|c|}{ University A } & \multicolumn{4}{|c|}{ University B } \\
\hline & \multicolumn{2}{|c|}{ Group 1} & \multicolumn{2}{|c|}{ Group 2} & \multicolumn{2}{|c|}{ Group 1} & \multicolumn{2}{|c|}{ Group 2} \\
\hline & Edits & Discussion & Edits & Discussion & Edits & Discussion & Edits & Discussion \\
\hline 1 & 69 & 06 & 36 & 13 & 03 & 00 & 05 & 03 \\
\hline 2 & 51 & 03 & 30 & 08 & 18 & 06 & 11 & 04 \\
\hline 3 & 02 & 01 & 65 & 10 & 12 & 04 & 01 & 05 \\
\hline 4 & 15 & 02 & 05 & 06 & 02 & 02 & 00 & 03 \\
\hline 5 & & & & & 36 & 09 & 00 & 01 \\
\hline 6 & & & & & 00 & 02 & & \\
\hline Total & 137 & 12 & 136 & 37 & 71 & 23 & 17 & 16 \\
\hline
\end{tabular}




\section{no. of posts}

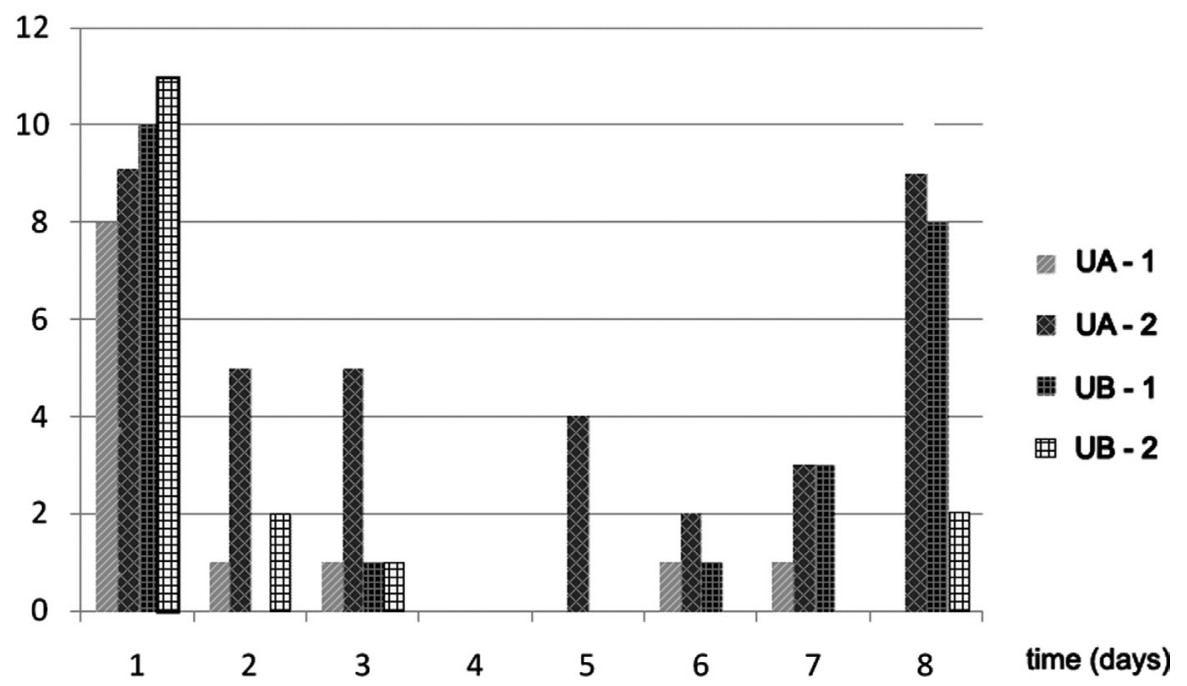

Figure 1. Distribution of discussion posts over time.

Figures 1 and 2 show concentrated activity at the start and end of the workshop period. Discussions for all groups were most active on Day 1 (Figure 1), although UA Group 2 made an equal number on Day 8. Editing activity was generally low to moderate in the early days, increasing on Day 8 (Figure 2). There was no UA activity on Day 4 because of the server malfunction.

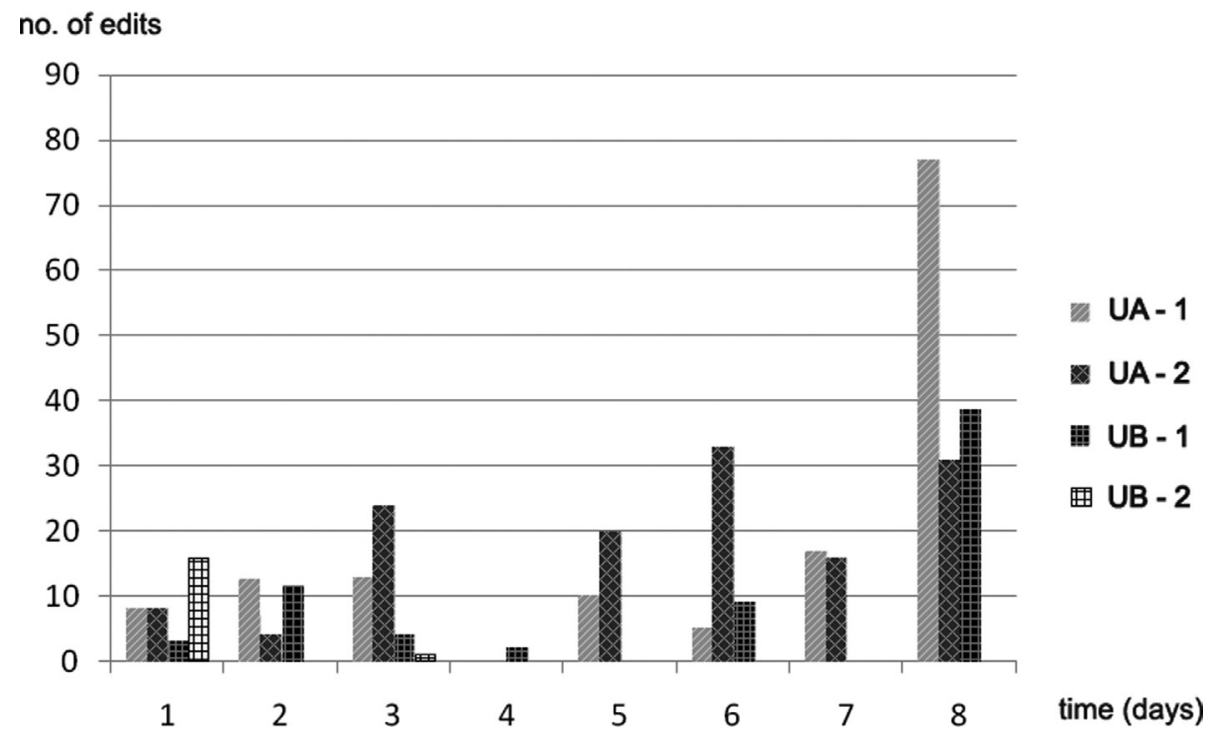

Figure 2. Distribution of edits over time. 


\section{The debrief}

\section{Critique}

Though the critique phase at UA was impeded by another server malfunction, two assessments of the Group 1 wiki and one of the Group 2 wiki were received, using the rubric provided. Comments on the Group 1 wiki acknowledged contributions to group organisation and output but critiqued it for the incomplete effort. Structure, navigation and layout were commended. The single Group 2 wiki assessment noted that two people had emerged as leaders and praised the communication effort and examples of individuals supporting each other. Accuracy, completeness and presentation were commended, with reservations expressed about lack of succinctness and use of animated graphics. All three assessments competently graded both the group effort and individual contributions.

At UB, two assessments of the Group 2 wiki were received but Group 1 received no assessment from Group 2. As indicated in Table 2, the UB Group 2 wiki had three contributors and was the least developed. Consequently, remarks on group work commended its early discussion and planning and critiqued it for not following plans through. The specific efforts of the two main Group 2 contributors were recognised.

\section{Reflection}

Seven UA and four UB participants contributed reflections. Overall, UA responses were more positive, though limitations of using wikis were expressed by participants from both universities. Participants' comments on the orientation, the task and benefits and limitations of wikis for teaching and learning are summarised below.

Orientation. All UA respondents regarded the orientation session as important, valuing and enjoying the experience for understanding online possibilities and initiating group work. While UB participants found the session useful, they noted the need for more time to get to know each other, "overcome the getting started barriers," and become "conversant with the technicalities of wikis."

The task. Three UA participants commented positively on the wiki task, using terms such as: "very enlightening" and "interesting." One found it an "interesting, irritating, enjoyable, boring, creative activity (almost all at once ...)." Further comments included: "I was amazed at the different (not better or worse just different) ways that the ... [task was] conceptualized" and "I would like to try using wikis with my students, but feel I am still in need of some support and advice." Participants identified potential uses of wikis for:

(1) "[providing] a repository of information which they [students] could access when out on fieldwork";

(2) "distance education, allowing group members to collaborate and learn";

(3) facilitating problem-based learning;

(4) "around the workplace"; and

(5) "working with academics/clinicians to collaborate."

All four UB participants who commented stated that the limited workshop time affected their level of contribution. Suggestions included providing a technical session as a workshop prerequisite and appointing a leader to ensure "that all 
Table 3. Some perceived benefits and limitations of using wikis in teaching and learning.

Benefits

Limitations

(1) Enhancing student ownership of learning objectives (UA)

(2) Reducing (or eliminating) the need to circulate emails (UA)

(3) Monitoring and evaluating student input into group work (UA)

(4) Avoiding use of track changes for collaboration (UA)

(5) Sharing information (UA)

(6) Facilitating tracking of individual contributions (UA, UB)

(7) Collaborative possibilities (UB)

(1) Losing contributions when group members are editing simultaneously (UA)

(2) Technology failures (UA)

(3) Trawling through pages for assessment cumbersome (UA)

(4) Managing multiple groups potentially difficult (UA)

(5) Engaging students potentially problematic (UA)

(6) Software lacks user-friendliness - technical knowledge required (UA and UB)

(7) Working collaboratively with unknown people difficult (UA and UB)

(8) Learning new skills requires effort (UA and UB)

(9) Making a regular time commitment (UA and UB)

(10) Relying upon collaboration of others (UB)

(11) Varying levels of participation (UB)

members participated appropriately." One suggested that "a range of exemplars would be useful" and perhaps some wiki templates for outputs such as research reports and presentations and group assignments.

Benefits and limitations. Participants identified more limitations than benefits of using wikis for teaching and learning (Table 3), three UA respondents referring to their age as an inhibiting factor.

\section{Evaluation}

An evaluation survey on each Blackboard site asked participants what they found most useful about the workshop, what they would change and provided space for additional comments. Six UA and four UB participants responded.

Most useful aspects. All UA respondents appreciated the opportunity to work with others as students in a wiki and learn about their potential for collaboration. Also appreciated were the supportive, continual input of the facilitators, the opportunity to become familiar with another online system, the support resources and the faceto-face session. Experiencing technical glitches was viewed as a positive learning experience. UB participants appreciated understanding the difficulties of working as a group online under time pressure, learning to use design components within the wiki and "[g]etting a clear view of a working wiki." They also mentioned the support resources and workshop task in helping to develop conceptions of how wikis can be useful in learning and teaching.

Suggested changes. Two UA participants advised extending the face-to-face session for practising while another recommended allowing more time to get to know group members and set roles and responsibilities. Other ideas included having fewer presenters and starting the session by explaining the potential and limitations of 


\section{R. Benson et al.}

wikis, followed by hands-on help in operating the application. To accommodate participants based at several campuses, videoconferencing the session was suggested. There was one request for tips to set up and manage student accounts and monitor multiple groups and edits.

UB participants also wanted a longer face-to-face session that incorporated the technicalities of operating wikis. Suggestions included having one instructor present the training while the others gave hands-on help (reiterating a point made in the orientation session evaluation) and commencing the workshop task at the face-toface session "so that the projects run smoother during the online components." The short workshop duration gave little opportunity "to do the norming, storming, and performing parts of teamwork, and if people are busy ... it's difficult to get into the task." They requested a longer (three week) workshop starting earlier in the year, fast and functional PC lab computers for the orientation, and the ability for participants to send email pop-ups to group members to advise site changes.

Additional comments. UA participants enjoyed the experience and appreciated the work involved and the difficulty of meeting the varied agendas of participants. One commented that it was a "great way to learn," including recognising the potential of technical problems and the time commitment required. UB participants reiterated that more time was needed to respond to the task and provide worthwhile feedback to others. One suggested that potential workshop participants be told that success depends on collaboration of all participants and that they should not register unless they had the time required. Participants from both universities were interested to see the wikis from the other university.

\section{Our reflections}

We noted the orientation session as a valuable design addition that facilitated group formation and technology familiarisation but recognised that both aspects required further refinement.

The additional support in group formation allowed participants to be more active in their wikis earlier and more effectively than in the first cycle, despite the hesitant participation by some members. Nevertheless, after initial orientation difficulties, the collaboration of those who participated did not appear to be inhibited by the technology but the requests for more technical help indicated their need for greater confidence. Through critical reflection and dialogue (Carr and Kemmis 1986), we concluded that lengthening the workshop would not increase participation, given the variability of contributions by participants. The importance of technical stability was illustrated by the experience of UA participants, with adverse experiences undermining the momentum of the workshop, their perceptions about the potential of wikis and their willingness to use them for teaching.

\section{Discussion}

Group interaction, task progress and group output showed marked improvement over the pilot workshop in the second cycle (despite variations between groups), suggesting the value of introducing the orientation session. Using the Blackboard sites for running the workshop was more successful than using another wiki because it distinguished between support via Blackboard and the sites for the workshop task. However, shortening the workshop and recruiting participants by advertising did 
not appear to assist in increasing commitment to the workshop by all participants. This highlighted the perceived lack of reward for participation, which also affected the pilot workshop and seemed to be a particular problem for UB participants. Some key implications for further development of the program are outlined below.

The orientation session evaluations (Table 1) indicated moderate to high levels of satisfaction but evaluation comments on this session and the workshop itself expressed concerns about the technical aspects of using wikis. These concerns could be addressed with more face-to-face practice, but there are also implications for ongoing support while the workshop task is in progress. This suggests a need for trialling different support options (e.g., printed support materials, online chat sessions, peer mentoring). Participant concerns also suggest a tendency for technology anxiety to undermine focus on pedagogical issues. This has implications for contextualising the introduction to the technology as part of the session to maintain the pedagogical emphasis (rather than treating it separately as requested by some participants), clearly articulating the pedagogical purpose of the workshop. Increasing the length of the orientation session would probably assist in this.

Workshop task progress showed an early phase of high discussion activity and moderate activity in wiki editing, followed by a lull, with a late phase of high editing activity but moderate to low discussion activity. This is consistent with collaborative group work in other contexts, reflecting an early task-negotiating phase leading to a co-operative phase where participants execute the tasks. Caution in analysing the data further is needed as the nature and significance of the contributions are not identified.

Variations between groups (Figures 1 and 2) may reflect common interests and ease in facilitation of the faculty-based UA workshops. This suggests that faculty or department workshops may be preferable to university-wide recruitment if tangible reward for participation (e.g., inclusion in a graduate certificate course) is unavailable. It may also help address evaluation comments, which emphasised the value of the experiential, collaborative nature of the workshop but expressed frustration with nonparticipating colleagues. Providing increased support for group work, fast tracking group formation and helping to establish a community of practice (Wenger, McDermott, and Snyder 2002) in the extended orientation session may also assist. Despite the intended role of the orientation in supporting group formation, the required levels of bonding and trust did not always develop sufficiently, particularly in UB Group 2. When participants fail to form functional groups in their wikis, their ability to engage with the task and to form a community of enquiry (Garrison and Anderson 2003) among themselves (and with us) is impaired.

The reflection and evaluation components of the debriefing provided useful information but the critique component appears to need greater emphasis if using a rubric to model wiki assessment is retained as an important aspect of the workshop. While the small number of UA responses (three) was probably influenced by the server malfunction, there were also only two UB critiques. This may indicate participants' discomfort in reviewing colleagues' novice wiki work.

In summary, key points in planning a third iteration of the workshop will be to:

(1) extend the orientation session to integrate technology familiarisation with the pedagogical purpose of the workshop, while reducing the number of presenters;

(2) improve group formation and increase participant responsibility to create a community of practice; 
(3) emphasise the role of critique during debriefing and its relevance to assessing group work;

(4) facilitate deeper reflection on the affordances of wikis for student group work;

(5) develop ongoing support strategies in these areas; and

(6) offer the workshop at faculty or department level if no reward is available for participation.

Thus, our experience has suggested that this online staff development model is potentially effective in helping staff to use wikis for student group work and assessment (Research Question 1). The main implications for improving the model that emerged over two action research cycles (Research Question 2) are outlined above. They indicate that action research was a useful approach for the iterative development of the workshop (Research Question 3), illustrating its practical advantages in informing this staff development approach (Kember and Kelly 1993; Norton 2009) and exploring innovative pedagogy (Laurillard 2008). Development of the model has contributed to addressing the need to prepare staff for online teaching (Wilson and Stacey 2004), relating to the particular opportunities and challenges that Web 2.0 technologies offer (Barnes and Tynan 2007; Dron 2007). Our findings support the value of a project-based approach for Web 2.0 staff development (Doherty 2011), by embedding it in an authentic, online context (Wilson and Stacey 2004).

\section{Conclusion}

This exploration of the experiences of a small number of groups at two Australian universities contributes to the more general need to explore ways to assist academic staff to use Web 2.0 applications for teaching and assessment. The case provides a model for the investigation of innovative staff development that is widely applicable and adaptable to other contexts through action research.

Making our enquiry public and available for peer-review, critique and exchange with others so that they can build on our work, as in our description of the first cycle of the development of this model (Samarawickrema, Benson, and Brack 2008, 2010), meets the definition by Shulman (2000) of a contribution to the scholarship of teaching and learning. By developing and investigating the effectiveness of this staff development model with its inbuilt capacity for improvement and adaptation through action research, our aim was to contribute to this field of enquiry, share the model itself so that others could use or modify it and, also, to illustrate the particular value of action research for engaging with the scholarship of teaching and learning (Norton 2009) by iteratively developing professional knowledge in this emerging area.

\section{Acknowledgements}

This paper was developed from a presentation made at the ISSOTL10 Conference, Liverpool, UK, 19-22 October 2010. We are grateful for an Outstanding Paper Award from the ascilite Auckland 2009 Conference for our description of the first iteration of this staff development model based on its relevance and wide applicability. The resulting invited journal publication (Samarawickrema, Benson, and Brack 2010), provided us with evidence of the contribution of this approach to the scholarship of teaching and learning. 


\section{References}

Barnes, C. \& Tynan, B. (2007) 'The adventures of Miranda in the brave new world: learning in a Web 2.0 millennium', ALT-J, vol. 15, no. 3, pp. 189-200.

Birch, D. \& Burnett, B. (2009) 'Bringing academics on board: encouraging institution-wide diffusion of e-learning environments', Australasian Journal of Educational Technology, vol. 25, no. 1, pp. 117-134, [online] Available at: http://www.ascilite.org.au/ajet/ajet25/ birch.html

Boshier, R. (2009) 'Why is the scholarship of teaching and learning such a hard sell?', Higher Education Research and Development, vol. 28, no. 1, pp. 1-15.

Brew, A. (2006) Research and Teaching: Beyond the Divide, Palgrave MacMillan, Houndmills, UK.

Brookfield, S. (1995) Becoming a Critically Reflective Teacher, Jossey-Bass, San Francisco.

Brown, J. S., Collins, A. \& Duguid, P. (1989) 'Situated cognition and the culture of learning', Educational Researcher, vol. 18, no. 1, pp. 32-42.

Carr, W. \& Kemmis, S. (1986) Becoming Critical: Education, Knowledge and Action Research, The Falmer Press, Lewes, East Sussex.

Doherty, I. (2011) 'Evaluating the impact of educational technology professional development upon adoption of Web 2.0 tools in teaching', Australasian Journal of Educational Technology, vol. 27, no. 3, pp. 381-396, [online] Available at: http://www.ascilite.org.au/ ajet/ajet27/doherty.pdf

Dron, J. (2007) Control and Constraint in E-Learning: Choosing When to Choose, Information Science Publishing, Hershey, PA.

Garrison, R. \& Anderson, T. (2003) E-Learning in the 21st Century: A Framework for Research and Practice, RoutledgeFalmer, London.

Grundy, S. (1995) Action Research as Ongoing Professional Development, Arts Accord Affiliation of Arts Educators, Perth, WA.

Guo, Z. \& Stevens, K. J. (2011) 'Factors influencing perceived usefulness of wikis for group collaborative learning by first year students', Australasian Journal of Educational Technology, vol. 27, no. 2, pp. 221-242, [online] Available at: http://www.ascilite.org.au/ ajet/ajet27/guo.html

Hutchings, P. \& Shulman, L. S. (1999) 'The scholarship of teaching', Change, vol. 31, no. 5, pp. $10-15$.

Kember, D. \& Gow, L. (1992) 'Action research as a form of staff development in higher education', Higher Education, vol. 23, no. 3, pp. 297-310.

Kember, D. \& Kelly, M. E. (1993) Improving Teaching Through Action Research, HERDSA Green Guide No. 14, NSW.

Kemmis, S. \& McTaggart, R. (2005) 'Participatory action research: communicative action and the public sphere', in The SAGE Handbook of Qualitative Research, eds N. K. Denzin \& Y. S. Lincoln, 3rd edn, Sage, Thousand Oaks, CA, pp. 559-603.

Laurillard, D. (2008) 'The teacher as action researcher: using technology to capture pedagogic form', Studies in Higher Education, vol. 33, no. 2, pp. 139-154.

Lewin, K. (1946) 'Action research and minority problems', Journal of Social Issues, vol. 2, no. 4 , pp. $34-46$.

Norton, L. S. (2009) Action Research in Teaching and Learning, Routledge, London.

Ruth, A. \& Houghton, L. (2009) 'The wiki way of learning', Australasian Journal of Educational Technology, vol. 25, no. 2, pp. 135-152, [online] Available at: http:// www.ascilite.org.au/ajet/ajet25/ruth.html

Samarawickrema, G., Benson, R. \& Brack, C. (2008) 'Teaching with wikis: addressing the digital divide', in ALT-C 2008: Rethinking the Digital Divide, eds N. Whitton \& M. McPherson, Association for Learning Technology, Leeds, UK, pp. 84-94.

Samarawickrema, G., Benson, R. \& Brack, C. (2010) 'Different spaces: staff development for Web 2.0', Australasian Journal of Educational Technology, vol. 26, no. 1, pp. 44-49, [online] Available at: http://www.ascilite.org.au/ajet/ajet26/samarawickrema.html

Schön, D. (1995) 'The new scholarship requires a new epistemology', Change, vol. 27, no. 6, pp. $26-34$.

Shulman, L. S. (2000) 'From Minsk to Pinsk: why a scholarship of teaching and learning?', The Journal of Scholarship of Teaching and Learning, vol. 1, no. 1, pp. 48-52. 


\section{R. Benson et al.}

Su, F. \& Beaumont, C. (2010) 'Evaluating the use of a wiki for collaborative learning', Innovations in Education and Teaching International, vol. 47, no. 4, pp. 417-431.

Surowiecki, K. (2004) The Wisdom of Crowds, Doubleday, New York.

Vygotsky, L. (1978) Mind in Society, Harvard University Press, Cambridge, MA.

Webb, G. (1996) Understanding Staff Development, SRHE and Open University Press, Buckingham.

Wenger, E., McDermott, R. \& Snyder, W. M. (2002) Cultivating Communities of Practice, Harvard Business School Press, Boston, MA.

Wilson, G. \& Stacey, E. (2004) 'Online interaction impacts on learning: teaching the teachers to teach online', Australasian Journal of Educational Technology, vol. 20, no. 1, pp. 33-48. 